\title{
Loading
}

The Journal of the Canadian Game Studies Association

\section{Playing the Past and Alternative Futures: Counterfactual History in Fallout 4}

\section{Samuel McCready}

Volume 12, Number 20, Fall 2019

URI: https://id.erudit.org/iderudit/1065895ar

DOI: https://doi.org/10.7202/1065895ar

See table of contents

Publisher(s)

Canadian Game Studies Association

ISSN

1923-2691 (digital)

Explore this journal

Cite this article

McCready, S. (2019). Playing the Past and Alternative Futures: Counterfactual History in Fallout 4. Loading, 12(20), 15-34. https://doi.org/10.7202/1065895ar

\section{Article abstract}

This article explores representations of history and history for the present in Fallout 4 to illuminate how the gameworld makes clever use of common historical tropes and aesthetics, as well as the genre of the counterfactual in its presentation of a compelling and interactive narrative. Set in the

post-apocalyptic landscape of Massachusetts, Fallout 4 employs various sites of historical Massachusetts (Concord, Lexington, Boston) in order to draw the user into the story of the 'lone survivor,' the avatar that he or she takes control of. This analysis is interested in the ways that Fallout 4 employs history and the genre of the counterfactual in the production of a compelling narrative that not only invites but impels the player into action to chart a new course for this devastated virtual landscape. The power of counterfactual history lies in its capacity to unravel assumptions about the static nature of historical events, and in its denial of a linear trajectory of history broadly. In the case of Fallout 4 , the implementation of a counterfactual story, wherein the nuclear event that shrouded the Cold War period in uncertainty, takes place. It serves as a rejection of the popularly rehearsed narrative of American supremacy triumphing over Communist forces to present the player with a more nuanced interpretation of some of the internal and external tensions that came to define the Cold War period (i.e. cultural malaise, economic instability, the growth of a military-industrial complex). This conflicting presentation of histories both real and imagined provides an opportunity for the player to experience and interact with the game critically as a counterfactual reimagining of the Cold War era. Viewed in this way, the virtual world of Fallout 4 becomes a space where the player can reassess their own understanding of the period, and the nature of historical knowledge production more broadly.
This document is protected by copyright law. Use of the services of Erudit (including reproduction) is subject to its terms and conditions, which can be viewed online.

https://apropos.erudit.org/en/users/policy-on-use 
Loading... The Journal of the Canadian Game Studies Association

Vol 12(20): 15-34

http://loading.gamestudies.ca

\title{
Playing the Past and Alternative Futures: Counterfactual History in Fallout 4
}

\author{
Samuel McCready \\ York University \\ sml.mccready@gmail.com
}

\begin{abstract}
This article explores representations of real and fictionalized history in Fallout 4 to illuminate how the gameworld makes provocative use of mid-century American aesthetics, culture, and topics in its presentation of a compelling and interactive narrative. In particular, I am interested in how Fallout 4 infuses a counterfactual rereading of the Cold War period into the game story, where the historical fear of Mutually Assured Destruction has become a reality, and the questions/challenges this raises for the player. The place of the counterfactual - which generally proposes a kind of 'what if' question in response to some historical event or actor (i.e. what if Hitler had launched a land invasion of Britain?), and proceeds to follow the thread that is generated - remains contested in academic history. However, I contend that the power of counterfactual history lies in its capacity to unravel assumptions about the static nature of historical events, and in its denial of a linear, logical, and progressive trajectory of history broadly. In essence, the counterfactual upends conventional and popular presentations of history and problematizes attempts to establish a 'narrative neatness' in representations of past events. Set in the post-apocalyptic landscape of Massachusetts, Fallout 4 unfolds in a variety of historical sites (Concord, Lexington, Boston), which serve to anchor the main story while simultaneously grounding a sense of optimism for the future in the tradition of "the American spirit.' At the same time, these virtual-historical landmarks and storylines reveal the major tension at work in the game, between the hopeful optimism associated with forging a new path forward and utter despair at the devastated state of this virtual world. The story and virtual aesthetics then, serve as a critique of the dominant narrative of American supremacy triumphing over communist forces to present the player with a more nuanced interpretation of some of the internal and external tensions that came to define the Cold War period (i.e. cultural malaise, economic instability, the growth of a military-industrial complex). This conflicting presentation of histories both real and imagined provides an opportunity for the player to experience and interact with the game critically as a counterfactual reimagining of the Cold War era. Viewed in this way, the virtual world of Fallout 4 becomes a space where it may be possible for a player to reassess their own understanding of the period and, importantly, their ability to critique and interrogate historical content and knowledge more broadly.
\end{abstract}




\section{Author Keywords}

Video games, history, counterfactual, narrative, critical play

\section{Introduction}

Writing in Digital Games as History, Adam Chapman (2016) remarks that "digital games, in a way quite unlike conventional historical forms, open up the story space to shared authorship... the historical narrative produced in these games is always produced by the actions of both the developer-historian and the player" (p. 34). This framing of the historical video game as distinct from other historical forms - in that it necessitates intervention and action on the part of the player - is helpful in beginning to explore the terrain of this genre (digital historical games) and its possibilities for the discipline of history. In his work, Chapman conjoins the ludic capacity of games with the storytelling drive in describing what he views as an emerging form that offers new ways of presenting and enacting history. Indeed, Chapman's work is primarily concerned with a dual analysis of the narrative and ludic elements of digital historical games in order to elucidate "not only what is said in digital historical games but also how it is said, by searching the formal structures that constrain and allow content, the stuff of history, to speak in different ways" (p. 18). Important for the present analysis is Chapman's emphasis on story (narrative presentation and authorship) and the crucial distinguishing of play (interactivity) as uniquely positioned in the video game form. For example, in historical strategy games such as the Civilization series (Sid Meier, 1991-2016), representations and engagement with the past are often explicitly conveyed to the player as a defined and strict system wherein history is expressed via interaction with a carefully constructed system of gameplay (tech trees, access to certain units, growth that is tethered to geography and climate).

In contrast, Fallout 4 (Bethesda Softworks, 2015) thrusts the player into a world deeply inspired by mid-century aesthetics/style, and informed by Cold War events, but leaves their engagement more or less free-form, where how they experience the historical content of the game is largely up to them. This is not to say that no constraints exist, or that no core (counterfactual) story attempts to direct player action in certain ways, but rather that it is the absence of explicit controls over player action in Fallout that speak most directly to the imperative of ludic engagement as it pertains to the narrative the game presents the player. Put simply, historical content in Fallout 4 is most explicitly expressed not as an intricate system of rules that a player employs or contends with, but by an absence of any cohesive sense of what 'history' is in a future America destroyed by nuclear war. The player is surrounded by history in Fallout 4, both real (families, culture, clothing, even suburban communities modelled on the 1950s and 60s) and fictional (atomic cars, fighting mech suits), but this history is fundamentally unsettled and unstable. There is no clear vision of the past, no definite relationship between what has come and what is now. All of these linkages have been upended by atomic war, and what is left is a world where history is ironic, playful, and crucially, uncertain.

This analysis is interested in how this system of ludic engagement (free-form and open-world) in conjunction with narrative, counterfactual storytelling, generates the virtual world of Fallout 4, and the possibilities that this game might afford for critical engagement with users. As such, the 
purpose of this article is twofold. First, it is interested in the ways that Fallout 4 employs history and the genre of the counterfactual in the production of a compelling narrative that thrusts the player into action to explore this world and chart a new course for this devastated virtual landscape. In so doing, it tasks them with making sense of this future world and its connection to histories both real and imagined. Second, I examine the possibilities for learning that may unfold through user interaction with this story. This is not simply a question of what Fallout 4 can teach a user about American history and Cold War society but rather how, through interactive gameplay, Fallout 4 may challenge the player's assumption of what history is, how it is told, who tells it, and for what purpose. As Chapman (2016) points out in his work, there is a case to be made that historical games provide the opportunity to educate players on the complexity of systems that make up historical analysis - the assemblage of facts, the constitution of 'fact,' the position of the historian, questions of agency and objectivity, questions of distance and genre among others (p. 279).

\section{The Counterfactual in History and Digital Historical Games}

In history, the counterfactual is a genre that normally focuses on a 'what if' scenario with regards to a specific historical event, person, place, period etc., and tries to imagine alternative outcomes to those inscribed in the historical record. For example, a counterfactual might ask 'what if Hitler's planned invasion of Britain had taken place and been successful,' and then pursue this question using the same historical materials and methods, as well as conjecture informed by those methods, as another historian might use in discussing the actual historical events. Counterfactuals in history emerge out of a larger tradition that seeks to question the nature of historical change and upend notions of linearity and objectivity that have tended to legitimize 'ways of being' as the inescapable outcome of a neatly unfolding past. This is not to say, however, that they have or do enjoy a privileged position in the hierarchy of historical practice. Up until the cultural turn and the emergence in postmodernism of a concern in history with its narrative form (White, 1973; Lyotard, 1979) counterfactuals were at best regarded skeptically if not outright dismissed as anachronisms, not histories. Indeed, writing in his seminal What is history? E.H. Carr (1964) referred to them this way: "these suppositions are theoretically conceivable; and one can always play a parlour game with the might-have-beens of history. But they have nothing to do with... history" (p. 97). E.P. Thompson (1978) similarly dismissed counterfactuals as "unhistorical shit" (p. 300) while Michael Oakeshott (1933) claimed that when events are treated counterfactually they "cease to be historical events," (pp. 128-145). However, with the work of Hayden White, Jean-Francois Lyotard, Michel Foucault, and many others, the empiricist-objectivist view of history (often expressed in positivistic terms) has largely retreated in academic scholarship, with new forms like micro, cultural, Marxist, and feminist history emerging in its place.

These perspectives have challenged the traditionally dominant tendency in history to write the past as a story of national or cultural progress, or to present history as teleological - one great movement towards a determinate end. Instead, they are interested in the tensions that exist within the production of history as a discourse; that is, in understanding how the policing of knowledge about the past and the stories that get told establishes and maintain hierarchies of power. Hayden White (1973) for example, writing on the narrative forms of history, has forcefully argued that history can not escape the historian's vision, that it must be acknowledged and accounted for, and this was simply the honest way to do history, not its demise: "I treat historical work as what 
it most manifestly is: a verbal structure of a narrative prose discourse. Histories combines a certain amount of 'data,' theoretical concepts for 'explaining' these data, and a narrative structure for their presentation as an icon of sets of events presumed to have occurred in times past" (p. ix). As White goes on to argue, his aim is hardly to denounce the doing of history or undermine the value of historical analysis, but rather to indicate "how ideological considerations enter into the historian's attempts to explain the historical field," and "to construct a verbal model of its processes in a narrative" (p. 26). The admission of subjectivity in historical making, then, is not to admit an inescapable relativism, but to acknowledge that ideology shapes all discourse, including historical theory and practice. This does not doom historical inquiry. Rather, it changes its trajectory, away from fantasies of positivist or objectivist linearity and towards understanding why, in the present, the conditions of power and knowledge are as they are, by examining the processes of their making.

Particularly crucial in the growth of the counterfactual and its gaining traction in historical scholarship was the publication in 1997 by Naill Ferguson and other contributors of Virtual History, perhaps the first full-throated defense of the counterfactual-as-history offered up in such a format. In it, Ferguson argues that "there is no privileged past," rather, "there is a multitude of pasts, all equally valid... at each and every instant of time," (p. 1). As such, the linear model of history that has long been suggested by objectivist-empiricist scholarship stands starkly at one side of the spectrum in a debate about the knowable past that has become increasingly complex, in modern historical theory. The work of historian philosophers has thrown into sharp relief the utter implausibility of a 'grand narrative' understanding of history, arguing instead that history (as with everything) is produced by and produces structures of formal style, agency, power, and relationships that deny the capacity for a singular vision of the past to take hold (Lyotard, 1979; White, 1973; Foucault, 1977). Ferguson infuses this understanding of contingency in his discussion of history in the following way: "the reality of history, is that the end is unknown at the beginning of the journey: there are no rails leading predictably into the future, nor timetables with destinations set out in black and white," (p. 70). The counterfactual then, serves simultaneously as a thought experiment and a corrective to the tendency for analysis to fall back on an empiricist-objectivist style. Though the use of alternative histories and counterfactual constructions of the past remain uncommon in historical discourse, their utility has become less subject to the fevered tensions and dismissal that once plagued the practice. This is due in large part to the careful way in which Ferguson and others have laid out particular rules for the writing of historical counterfactuals that constrain the genre's most outlandish potentials. For instance, Ferguson argues that, "we should consider as plausible or probable only those alternatives which we can show on the basis of contemporary evidence that contemporaries actually considered," (p. 86). Understood in simple terms, this highlights the distinction in a potential historical thought experiment between, say, whether Hitler had successfully defeated Britain in 1940-41 (which was a very real possibility) and whether Napoleon would have defeated Wellington at Waterloo had he only had a couple of C-three Leopard tanks (an obviously untenable consideration). By reigning in the parameters of what can constitute a useful and potentially insightful counterfactual investigation from a superfluous one, Ferguson and others have helped to legitimize a genre of historical analysis and writing.

Shifting to the position of the counterfactual in digital representations/enactments of history, Johannes Koski (2017) points out in his work on Valkyria Chronicles, a counterfactual historical 
game about the Second World War, that one of the critical benefits of the counterfactual is that it lays open to the player many of the questions regarding the ideological underpinnings that motivate historical making: "Valkyria Chronicles is about history-in-the-making, about the transformation of events into history, and about how they are retold to those who come after the events transpired. The player gets to see in some limited ways the subjectivity of history at play; how the choices we make end up affecting what gets written down" (p. 409). This also addresses one of the key questions that scholars who work on historical games are quick to point to in their criticisms of these games, by revealing how games like Valkyria Chronicles stake a position that denies the possibility of objective interpretive position wholesale, instead acknowledging that the historian-as-individual inevitably brings a unique subjectivity to any investigation (in history or any other subject) that they pursue. It is often cautioned that playing an historical game can cloud an individual's understanding of the 'pastness' of the past, because they are injected into history as an actor and are therefore more inclined to engage with and internalize history in a personalized (rather than neutral) way. However, the satirical and openly playful approach that counterfactual games take to representing the past works to dispel some of the concerns scholars have about students using games as a means of approaching or accessing the past. What is being interacted with in these games are not real historical actors or concrete historical settings, but rather historically rich worlds that challenge and raise questions about hermeneutical frameworks of historical making. That is, about how it is that historians come to interpret the past in particular ways, and more importantly why this might be so.

In Fallout 4, the genre of counterfactual is used to throw out assumptions about mid-twentieth century culture and look instead at other possible outcomes, had history unfolded in a different way. Outside of the game world, in the post-Cold War era, the narrative that American nationalist history latched onto quickly became one of capitalist (and American) domination over communism, where the outcome of neoliberal historical progress was always clear and a new global culture grew out of the supremacy of that unique brand of American consumerism. As Francis Fukuyama (1992) famously proclaimed in the wake of the collapse of the USSR: "the twin crises of authoritarianism and social central planning have left only one competitor standing in the ring as an ideology of potentially universal validity: liberal democracy, the doctrine of individual freedom and popular sovereignty" (p. 42). For Fukuyama, the fall of the wall in Berlin signaled the end of history's most profound struggle, a conflict he described as the "problem of recognition," (1991, p. xxi). In its place, neoliberal democracy and capitalist economies offered the closest possibility to a 'universal ideology' that could ultimately settle the issue of personal freedom and individual recognition. In providing an alternative future landscape, Fallout 4 throws into sharp relief the reality of the anxieties that characterized the era, and further denies the construction of history to suit capitalist economic and geopolitical interests. Games like Valkyria Chronicles and Fallout 4 generate worlds that raise questions regarding historical contingency, bias, ideology, and power by admitting openly that they serve as playful stories related to the past without claiming to be faithful imitations or reenactments of a period or place(s) in history. This makes them no less impactful as sources for historical insight. Instead, they propose questions about the discourses and discipline of history and its study, by troubling conventional wisdom and accepted narratives that have become rehearsed in popular media and in the classroom. Put another way, the point of focus becomes not whether Fallout can teach the user about the Cold War in vivid detail, but rather what this story - borrowing heavily from a 
particular interpretation of the Cold War period - reveals to the user about the nature of historical knowledge and the processes that underlie its production and legitimization.

\section{Historical Game Studies}

While it is impossible to point to a singular starting place for the emergent field of historical game studies, surely Kurt Squire's (2004) work on Civilization and history learning and William Uricchio's (2005) seminal piece "Simulation, history, and computer games," stand apart as laying the groundwork for future research. Uricchio argues for historical computer games "as sites to tease out the possibilities and complications of historical representation and simulation," further claiming that "games by definition subvert the project of consolidation and certainty associated with the former brand of history [postivistism]... predicated as they are on a reflexive awareness of the construction of history" (pp. 328, 333). Meanwhile, arguing for the potential of historical games in education, Squire (2004) noted in his doctoral work that "Civilization III represents history... as an emergent process arising from overlapping, interrelated factors... successful students [playing the game] developed conceptual understandings across world history, geography, and politics" (Squire "Replaying History"). Building on the foundations provided by Squire and Uricchio, Matthew Kapell and Andrew Elliot (2013) argue that "the ludic (play) capacity of historical video games allows for in-depth understanding not just of the facts, dates, people, or events, but also of the complex discourse of contingency, conditions and circumstances, which underpins a genuine understanding of history" (p. 13). Centering the ludic element raised by Uricchio, then, Kapell and Elliot argue that the necessitated interactivity proposed by historical games provides unique opportunities not simply to view or experience history narratively and aesthetically, but to participate in it.

Most importantly, the intervention of the player within the represented past of the game has the effect of highlighting the contingency of decisions that shape outcomes. This raises the spectre of the counterfactual as one genre that incorporates contingency at the core of its storytelling and aesthetic philosophy. Indeed Tom Apperley (2013b) notes that "digital games... offer a mode of engagement with an alternative historical text that provides an opportunity for the player to consider critical and reflexive interpretations of historical events" (p. 186). In much the same way as the counterfactual novels of Phillip Roth focused attention on specific (and often unrepresented) issues ongoing in America during World War Two, counterfactual games problematize simplistic readings of past events that tend to get reduced into a kind of casual chain that denies contingency and reifies the 'accepted' story. This is of particular concern to academic history, which is constantly in tension with the institutional designs of historical learning so often completely reliant on textbook renderings of the past that have an overwhelming tendency to greatly oversimplify or connect together events into a form-fitting narrative. Too often in conventional history education what is neglected are the questions most central to understanding the discipline and practice of history: who is writing academic history? Who is included and excluded from the dominant narrative of intellectual or national progress? What subjects get to constitute 'legitimate history'?

However, the rise of digital forms of historical representation and presentation have not been met with unanimous enthusiasm by any degree, and there remains an ongoing debate regarding the 
constitution of scholarly 'history' over and against its popularized forms (like games) and whether or to what extent emerging historical forms fit into the rubric of traditional, text-based history. Scholars like Jerome De Groot (2006) for example maintain a skepticism regarding the possibilities of historical games to represent the past, noting that in ostensibly historical games like Medal of Honor and Call of Duty the player "is invited into a history," but claiming that it is "a wittingly small part of a teleological move towards the present," and thereby casting doubt on the claim that historical games demonstrate the contingency of events by suggesting that the lack of freedom provided to the player structurally (the inability to skirt the games strict rules) essentially places them within a teleological paradigm that presents history as unfolding in a neat casual sequence (p. 409). In other work on public history, De Groot notes that "game shows, pub quiz nights, and board games present history as a set of facts which are correct," and further that their "underlying ludicness [...have] little innate value outside the game structure" (pp. 7-8). In a similar vein (though not specific to games), while highlighting the broadening of popular historical forms as a result of the increasing embracing of history as narrative since Hayden White, David Lowenthal (2007) argues that "the new chaotic past is too chaotic to comprehend, those unschooled ever less able to absorb it... our collective legacy grows more bewildering than enlightening" (p. 209). Certainly for Lowenthal, historical games fit within this milieu of new historical forms that seem to provide as much obfuscation of that past as clarity, especially counterfactual games that begin with the premise of alternative history. I fully acknowledge the concerns about historical games and their value that are raised by De Groot, Lowenthal, and many others (Rejack, 2007; Hess, 2007; Kee, 2011; Metzger \& Paxton, 2016), most especially the call made by many researchers on historical games for a cautionary approach that remains mindful of the limitations of digital representations and reenactments of history. However, I maintain that by upending the enshrining of historical revisionism that dominates (especially) the textbook form, and linear historical narrative more broadly, complex counterfactual renderings of a particular past (like Fallout) gesture towards the multiplicity of factors that go into generating any historical interpretation, both those unapologetically fictional and those that stake a claim as real representations of the past. As such, they present an opportunity for their users to engage with historical material in a critical way that can raise questions about historical knowledge and making, and the processes that underlie its production and legitimization.

\section{Fallout 4 and the Cold War That Wasn't}

\section{Background}

Fallout 4 opens in the home of the protagonist (male or female, player choice) in the year 2077. The home is located in an idyllic suburban community called Sanctuary Hills and both the layout and name of the community are plainly reminiscent of the kinds of intentionally designed urban utopias that began emerging in America in the mid-twentieth century. Indeed, one quick scan of the home and neighboring community (see Figures $1 \& 2$ ) is enough to locate the aesthetic of this futurescape firmly in a mid-twentieth century consciousness. 


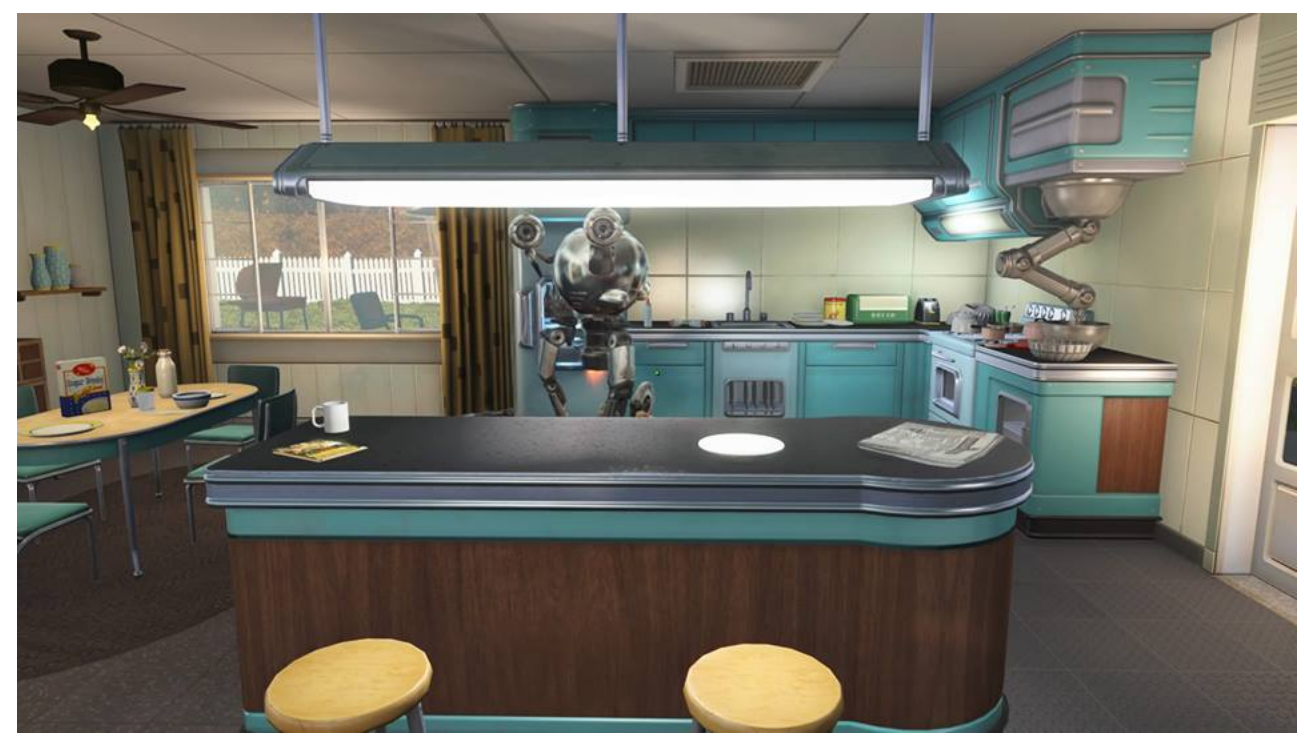

Figure 1, kitchen in Sanctuary Hills

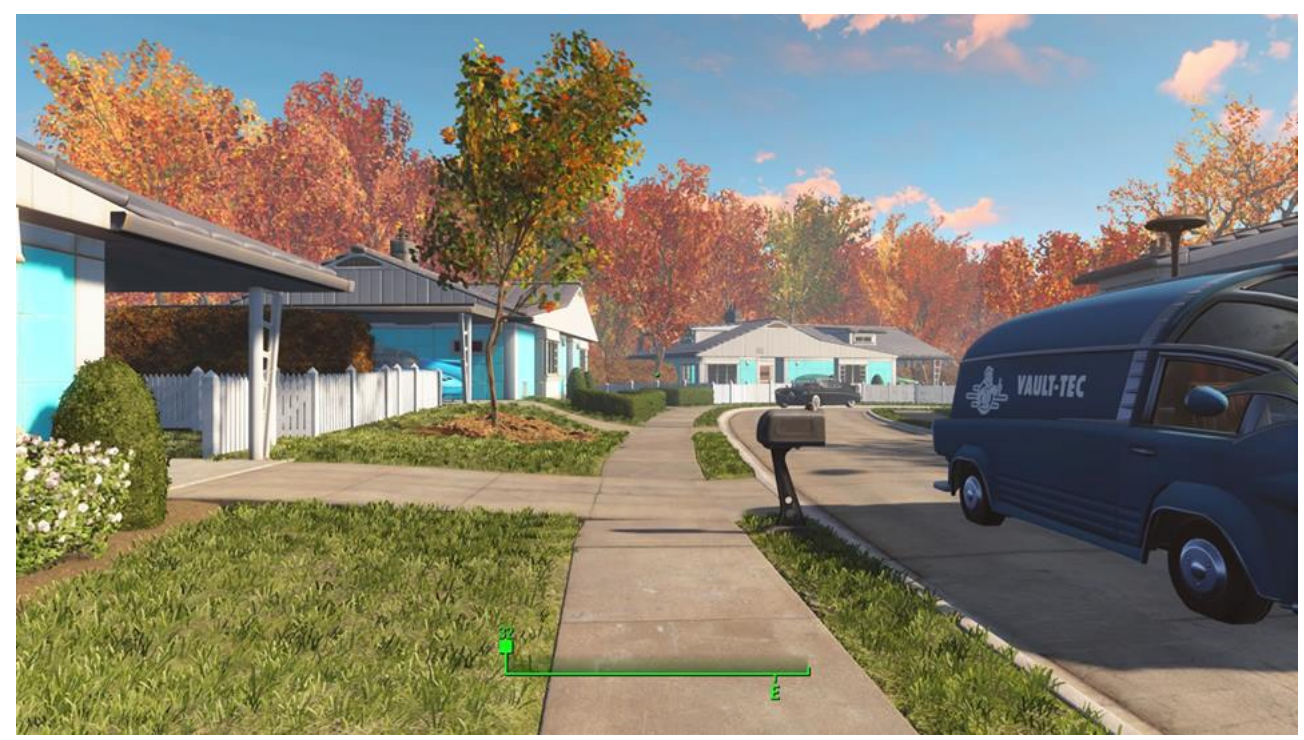

Figure 2, Sanctuary Hills

The inclusion of the standard metal mailbox and white picket fence, as well as a kitchen full of classic metal appliances, attests to the projection of a nostalgic historical aesthetic into the future. Indeed, Fallout's official wiki makes clear, "for most of human history, the Fallout universe and the real world shared a common timelime" (Fallout Wikia, 2017). The primary break with the present timeline occurs immediately following World War Two, where in the Fallout universe an explosion in nuclear technologies ushers in a "techno-utopia," as Joseph November (2013) refers to it in his own work on Fallout 3 (p. 298). The focus on nuclear innovation also stymies other projects, so for example in the world of Fallout the transistor and microprocessor are never invented, resulting in the future world that largely maintains a mid-century aesthetic. Talking servant robots are tubular rather than anthropomorphic, and nuclear powered cars sit in 
driveways while the latest computer technologies continue to be big and unseemly (see Figure $3)$.

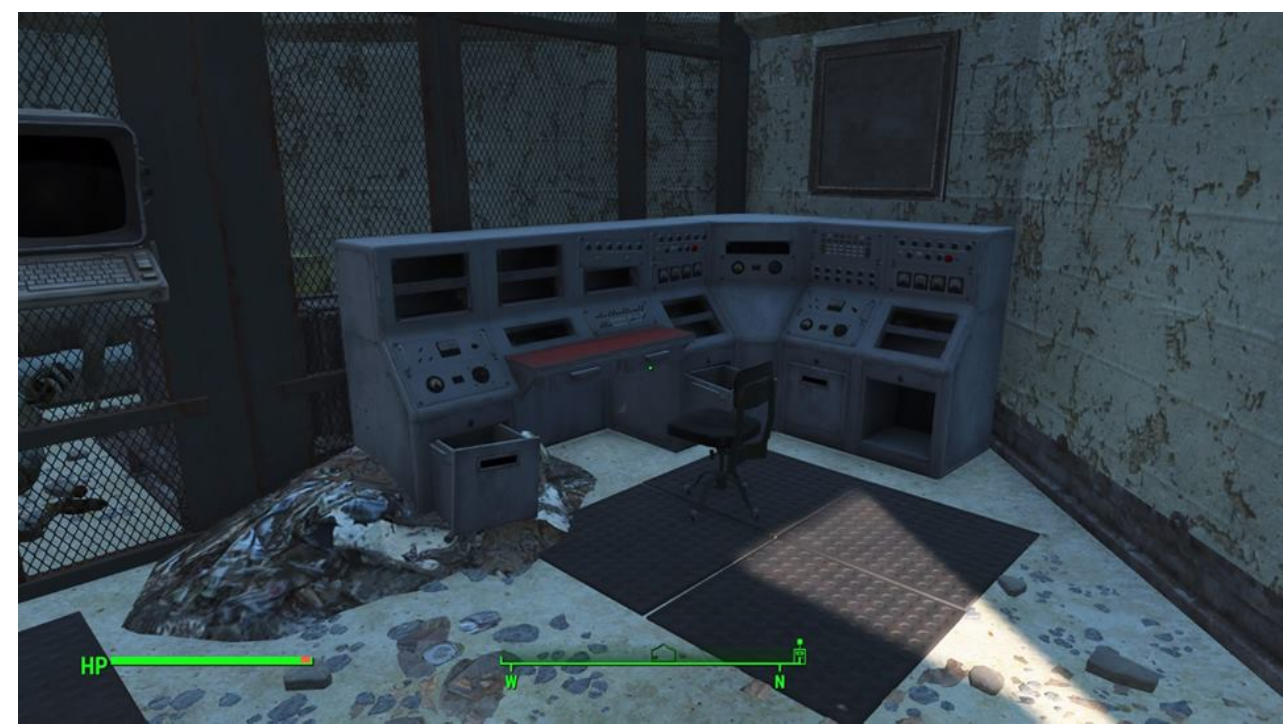

Figure 3, computer terminal, Fallout 4

Importantly, this contrast between the future setting of Fallout and its dated aesthetic style, forms one centerpiece of the counterfactual presentation made by the game. November's work on Fallout 3 in particular (all games in the Fallout universe occupy the same timeline and worldscape) argues that one counterfactual in Fallout is contained in the presentation of this 'what-if' question regarding what the future might have looked like if America had continued its non-military, technology-centred nuclear project, following the end of the war (pp. 301-304). For present purposes, what is most important is a recognition of the way that Fallout 4 is stylized as a futurescape that is rooted in mid-century visions of a 'techno-utopia,' however far this gameworld actually comes to satisfying this utopic desire notwithstanding, and how this internally logical alternative future can provide a critical mirror to see the contingency of the historical period it intends to represent.

Of course, the idyllic suburban image that opens the game quickly shatters for the player. First, a representative visits them from 'Vault-tec,' a company centred on the production of massive fallout shelters in preparation for a potential nuclear war. There is, after all, still a Cold War between America and its communist enemies in Fallout, as the nuclear technology race makes sure to keep tensions flared between countries long into the twenty-first century. Clearly nervous, the Vault-tec rep tells the player that because of their distinguished service (as a veteran) they have been granted a place in vault 111, while also issuing a warning that the end is near: "Vault-tec Rep: If you'll excuse me language. The big kaboom is... it's inevitable, I'm afraid. And coming sooner than you may think, if you catch my meaning" (Bethesda Softworks, 2015). Almost immediately upon accepting his offer for a place in the vault, the TV begins issuing reports of explosions all over the East coast, confirming that nuclear war has begun. The player is ushered from their home and towards vault 111, where they are (unknowingly) cryogenically frozen for some 200 years, awakening in the late 2200 s, when the game-story begins. Set in the Boston metro, and paying homage to historical Massachusetts landmarks (in places like Lexington, Concord, Cambridge, and Boston itself) Fallout 4 offers the setting of an 
America in the twenty-third century that has been devastated by total nuclear war, and follows the player as they explore and attempt to bring some semblance of stability to the violent 'wastelands'.

\section{Playing an Alternative Future as Past:}

Ideally, this background is meant to help explain how a game like Fallout 4, ostensibly set in the future, can possibly serve as the site for engagement with the past. Immersed as they are in this futurescape, players are reminded constantly of the world that was, both as a consequence of aesthetic setting(s) and the narrative the player becomes entangled in. In both respects, Fallout unfolds as a story about a Cold War world where 'the button' no longer stands in as mere metaphor to the forgotten doctrine of Mutually Assured Destruction that informed much of the 'panic culture' of the mid-twentieth century. What follows here are a number of examples drawn from gameplay meant to illustrate moments of interaction with the gameworld where this alternative future intersects with a past that 'could have been'. These examples are meant to illuminate a critical function of the counterfactual, both as it unfolds in this game and in general: that 'what is' could have been otherwise, and therefore that the future itself is multiple, open to the same contingencies that shape history in any given moment. This is by no means intended to serve as an exhaustive survey, but rather as an introductory exploration of Fallout 4 as counterfactual, and I am sure many excellent examples not mentioned here could easily be added, given the free-roam structure of play and incredibly layered stories Fallout offers player's access to. Emerging often in spite of a prevailing tendency to situate history as primarily a story of military and capitalist supremacy (a perhaps unsurprising vision of American greatness levied as it is on military prowess), the counterfactual in Fallout problematizes this veneer of history by scattering evidence of its catastrophic consequences throughout the wastelands.

The tone of counterfactual is set most explicitly in the game by the virtual environment, as a striking and all-encompassing testimony to the devastation brought upon this part of the world by nuclear war. Considered as a 'what if' with regards to the real possibility of mutual nuclear annihilation once felt as a common anxiety, scattered throughout the wastelands is evidence of these past tensions on a micro-level, advertisements for example that capture simultaneously a sense of optimism and pessimism left over from the pre-war period. At the same time, the landscape of the game is permanently scarred by this past conflict, which darkens not only the aesthetic style of Fallout but the tone of the story as well. Crafted with a heavy dose of irony, any number of leftover billboards or other kinds of advertisements that the player comes across in the wastelands, captures both the optimism of a past age while subtly revealing the anxieties constantly in tension with this vision of the past. Often this is done simply by way of the advertisements' imposition in a particular place that also bears the ravages of war (and two hundred plus years of slow erosion). Take for example an advertisement for cereal and a local supermarket pinned to a poster-board in a bombed out building (see Figure 4). The aesthetic styling of the advertisements is one of bombast, with products and incredibly enthusiastic consumers featured front-and-centre. Certainly as expressions of consumer culture, they act as a shameless (and playful) endorsement of consumer goods and thus consumerism (big bold letters, the heavy use of red as a signifier of exaggerated excitement, the smiling child featured next to the bowl of cereal, the happy shoppers featured on the other advertisement etc...). 


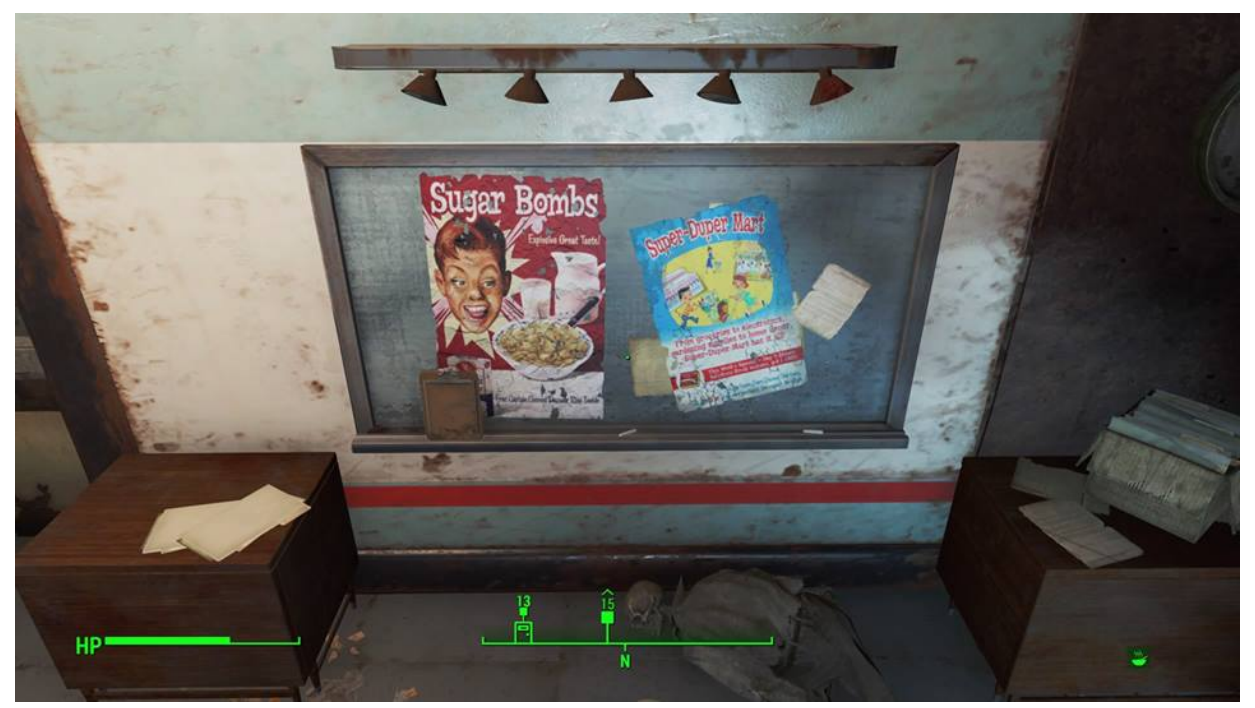

Figure 4, pre-war advertisements

Yet, its placement in this bombed-out building offers a telling contrast between the optimism on display in the advertisement and the reality of the (in-game) present. Consider for example the general darkness of the setting, the moldy box of illegible files sitting on the desk to the right, or the rusted lights hanging above; and of course it is impossible not to notice the skeletal remains of a person unable to find refuge when the bombs fell. All over the wastelands are advertisements like this one, that harken back to an idyllic past but simultaneously force the player to reckon with the bleak conditions of the present (and thus of the counterfactual postapocalyptic landscape), transfixed as they are against an environment that bears the markings of nuclear war. This juxtaposition of happy consumer culture with total annihilation serves as its own critique of the kinds of excess that are at least in part responsible for for the destruction that has been wrought. Additionally, this contrast of images denies consumer culture and capitalism their claims as utopic agents of change by illustrating to the player that no corner of the capitalist marketplace remained safe from the devastations of the war.

In a more visceral way, the player need only look in front of them while exploring the openworld in Fallout to see constant reminders of the 'Great War' (how the denizens of the wastelands refer to the nuclear event). The contrast between hokey advertisements for 'sugar bombs' or 'nuka cola' (the most popular drink of pre-war America and the present day wastelands) cleverly highlight the tension between the optimism in an earlier age and the realities of a much more somber present. In terms of setting a narrative tone and bringing the counterfactual world of Fallout to life, the destruction that surrounds all views in the gameworld undermines any attempt to salvage a positivist project of the past. Take just two images (see Figures $5 \& 6$ ) captured from the open world of the game. In this destruction of a past and the precariousness that ensues for all futures, there can be no story of blind optimism leading to victory, of capitalism subsuming inferior economic models or American military prowess overcoming evil communist forces. 


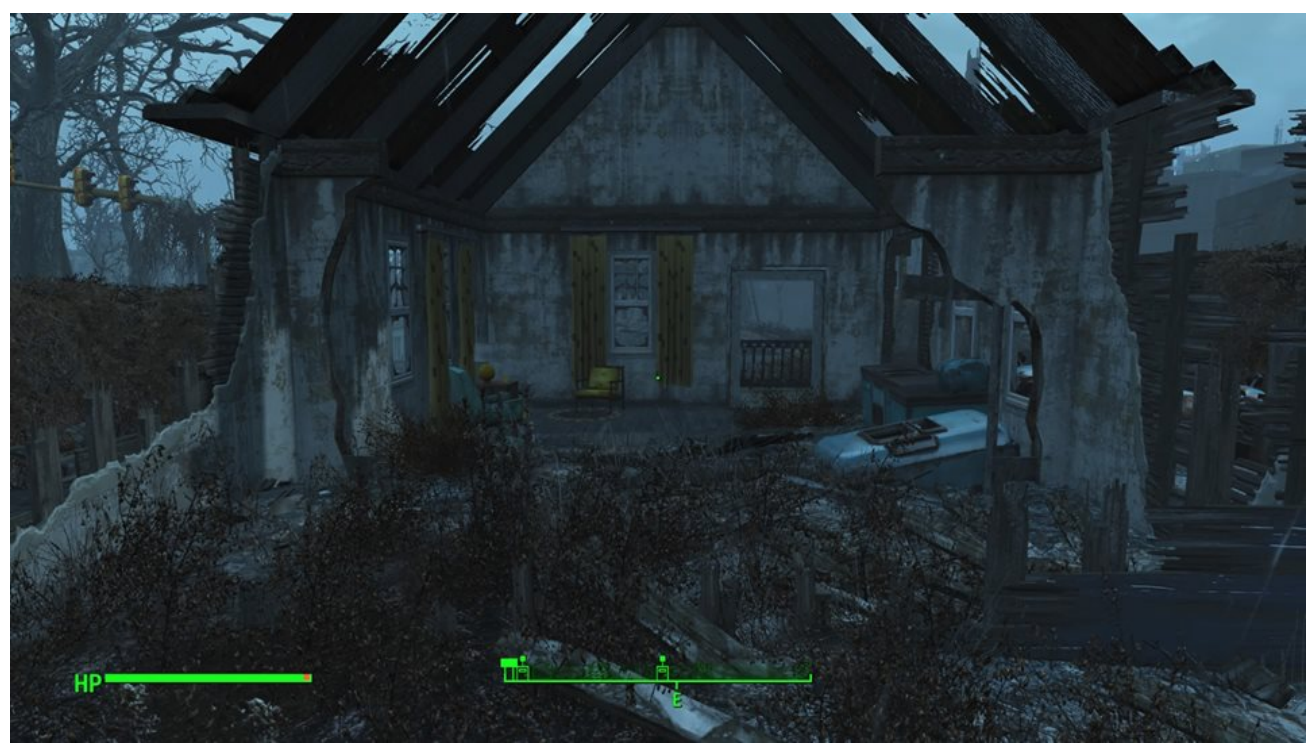

Figure 5, bombed out house in Fallout 4

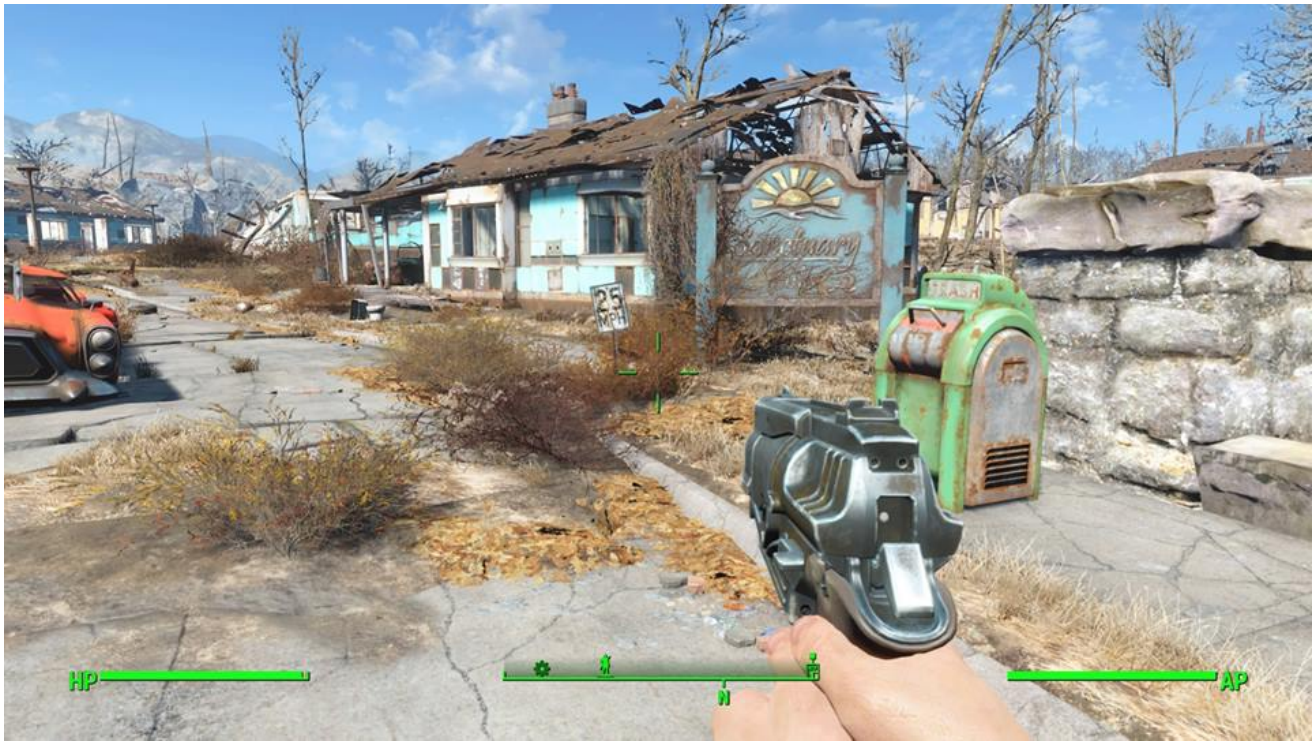

Figure 6, Sanctuary Hills post-Fallout

By considering one plausible scenario (what if the bombs had fallen?), Fallout reveals the tenuousness of the historical trajectory that proceeded from that mid-century moment until the present in its own altered futurescape, and makes a powerful claim against totalizing and revisionist attempts to reconstruct an ordered version of events in which it was always (if subtly) obvious who the victors would be. Any number of arguments can be extended from this, and all are - to some extent -valid interpretations of the gameworld: cautions against nuclear-buildup; a problematizing of mass consumer culture; an argument against techno-utopia ushered in by unchecked technological progress and the vastly unequal world this engenders; or simply the dangers of a runaway military-industrial complex. Most importantly, any of these arguments relies upon an understanding that the nuclear catastrophe in Fallout serves as a 'what if' scenario about a past time even if the game is ostensibly set in an altered future. In interacting with this 
space, players are forced to orient themselves in a world where both the logic of progress, and dominant historical narratives that serve to order the past in the service of ideology, have come undone. In their absence, an opportunity emerges both to see how these narratives work to shape and solidify hierarchies of power, and to critique them, since if nothing else is evident to the player is it inescapably clear that these ordering mythologies have failed spectacularly to create a better future.

I wish to briefly examine one particular location in the game - The Museum of Freedom, one of the first areas the player encounters - because it neatly brings together some of the key tensions expressed by the game between militarism and destruction. The building itself is largely intact, though clearly affected by the bombs (debris is scattered everywhere, along with parts of collapsed floors and staircases), and maintains a striking tribute to America's military past, stemming from the revolution, to the moment of historical departure for the Fallout universe, and finally up until the brink of nuclear war. In a way, this building and its contents tell a story about American history which is itself upended as a consequence of the nuclear event; that is, the story offered by the museum is largely linear, one of succession from revolutionary war to World War and American dominance, and yet both the building itself and its contents openly reveal the fallacy of this trajectory even while they attempt to advance it. For example, strewn about building are portraits in various states of decay, presumably of past American heroes (see Figures $7 \& 8$ ) that at one and the same time desire to project a continuity of the American experience (what defines American spirit in the context of history) while evidencing the radical break wrought upon history by nuclear annihilation and the end of 'civilization.'

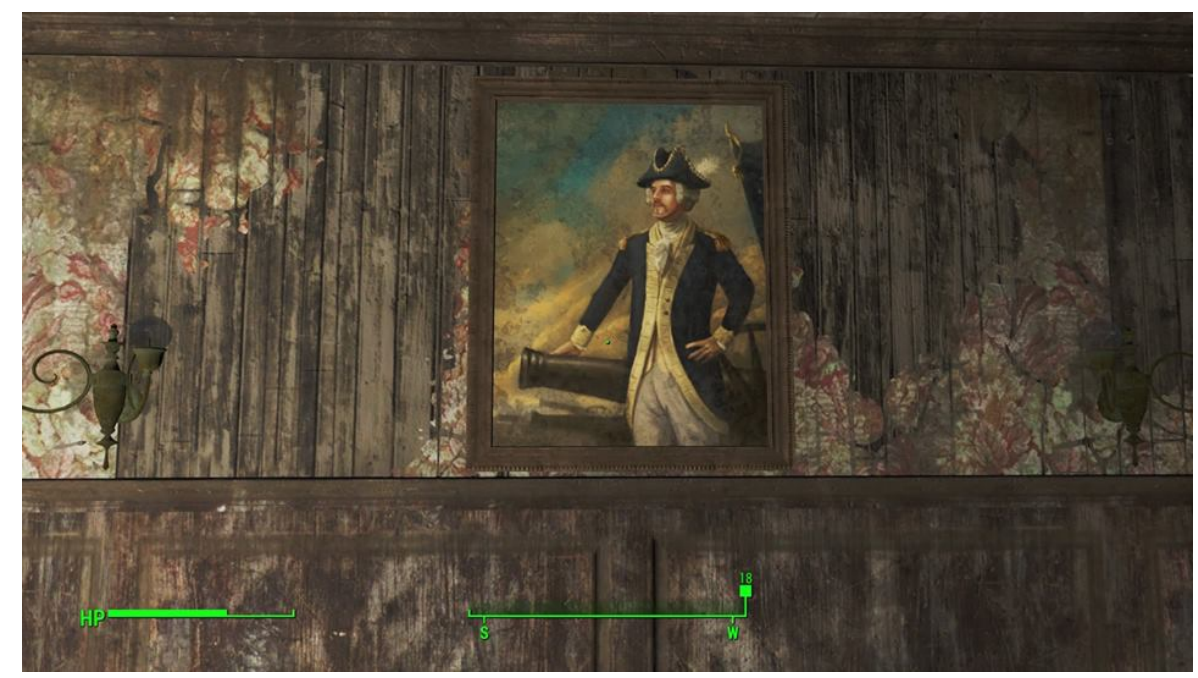

Figure 7, portrait from the Museum of Freedom 


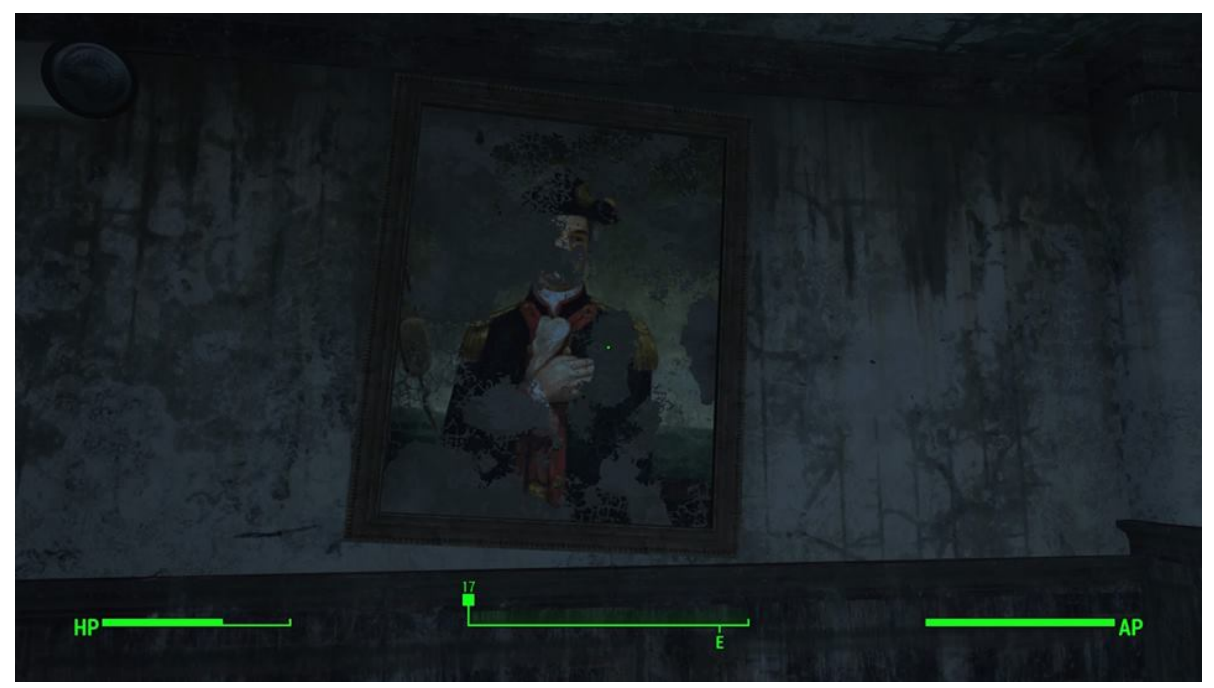

Figure 8, faded portrait from the Museum of Freedom

Put another way, while certainly at one moment these portraits served the purposes of a narrative chain connecting America's past and present in a series of moments that came to define the unique quality of 'American spirit,' they are no longer able to carry forward this story of history, given the fundamental break ushered in by the nuclear reality, and evidenced (in part) by their various states of decay. If anything, these slowly eroding images reflect the present tenuousness of logical historical continuity (or of history as a narrative of progress), and an overwhelming cognitive dissonance experienced as a consequence of the nuclear war.

Of particular interest in the museum is a mural offered as a timeline and tribute to all of America's fallen, from the moment of revolution to the final conflicts before nuclear war. The tapestry is highly detailed, and narrates visually the story of American military history, capturing neatly a causal chain of historical events (see Figure 9). Yet, enclosed as it is in a building that bears the scars of the 'Great War,' the mural is particularly striking for the contrast that it provides for the player between a past defined in large part by military prowess and a present that has suffered so much in part because of this runaway militarism. This, like many other examples in the museum and the larger gameworld, provides an opportunity for the player to consider the problem of a runaway military-industrial complex in their own present. 


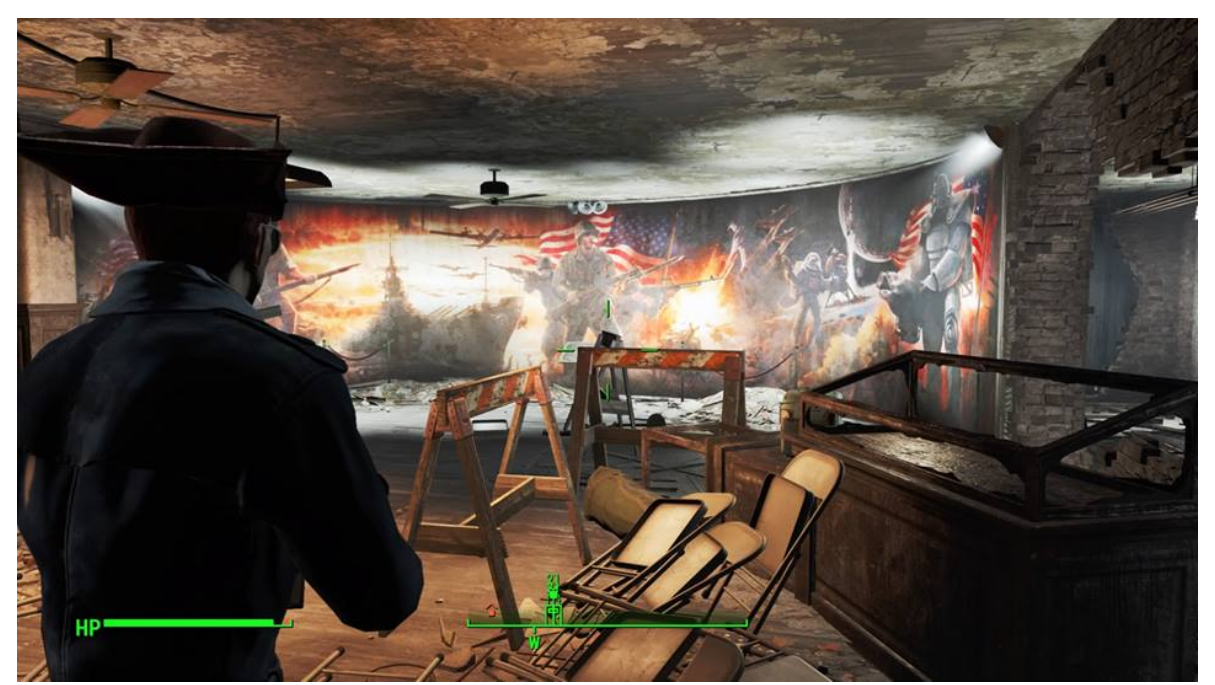

Figure 9, mural representation of American military history, Museum of Freedom

Perhaps as no other image in Fallout does, this mural brings together the real past, with the moment of alternative departure (in the advancement of atomic technologies such as the powermech armor suit) in the Fallout universe, to an alternative future defined by nuclear apocalypse, almost as a layering of counterfactuals that constantly refer back to an excess of naïve optimism for the wonders of atomic technology and a blind posturing (emphasized in large part by mass consumer culture) that culminated in catastrophe.

The mural further extends itself in the narrative of Fallout via the games various factions that the player interacts with. It is in coalition (or opposition) with many of these groups that the major story of the game unfolds. Interestingly, all of Fallout can be connected to the visual story of the mural in crucial ways (suggesting perhaps a narrative continuity with this rendering of the American past) that both activates American history and reveals its present uncertainty. The Minutemen for example, the first major faction that the player encounters, bears obvious resemblance to the revolutionary militias from which the group borrows its namesake, both in aesthetic style (the only uniformed member, Preston, wears fatigues strikingly similar to popular depictions of historical militia attire) and guiding philosophy. The goal of the group, expressed piecemeal by Preston and others, is to unite the scattered survivors of the wastelands - or 'commonwealth' - together in the name of freedom and peace, and to bring stability back to the region. As an organization, the Minutemen favor freedom and the revolutionary spirit above all, and consistently demand that the player act altruistically, putting himself or herself in danger for the cause. In a generally pessimistic atmosphere, the Minutemen serve as figures of optimism for a better future:

Preston Garvey: You know, you remind me of my friends. The other Minutemen, the ones who gave their lives for something bigger then themselves.

Preston Garvey: The Minutemen were the only good guys around really... I still believe the Minutemen can be what I always thought they were, the good guys.

(Bethesda Softworks, 2015).

The faction maintains the revolutionary spirit expressed succinctly in the mural at the Museum of Freedom, and traces their evolution back to revolutionary figures like Washington, highlighting 
the importance of historical reference even in a future world where utopic visions of the past have been ruptured by conflict and destruction.

By contrast, the Brotherhood of Steel, another faction the player encounters early, embodies the continuity of militarism between past and future. Present in other iterations of the Fallout universe as well, the faction orders itself along a classical military design (order, discipline, ranks, obedience) and styles itself as the only source of stability amidst the chaos of the wastelands. The group demands strict adherence to its structures and orders:

Paladin Danse: If you intend to stay within our ranks, you need to obey our tenets without question

Paladin Danse: I only ask for two things under my command - honesty and respect. You fall in line and you stay in line. I give you an order, and you follow it. It's as simple as that.

(Bethesda Softworks, 2015).

The faction views the mass consumer culture of the previous age with disdain, but applauds the technological wonders that defined this period, seeking to locate, preserve and (perhaps insidiously) claim a monopoly over their use in the present period. Indeed, in Fallout 4, the Brotherhood possesses technological superiority over all of the games' other factions, save for The Institute - a group of scientists that originally fled underground before the bombs fell - and they desire to exercise control over the future of the 'commonwealth' through this exploitation of coordinated military power. Clearly, the Minutemen and the Brotherhood propose two contrasting visions for the future, even while they both rely heavily on an understanding of the past such as that which the mural in the Museum of Freedom serves as a striking reminder of. In different ways, however, the narrative arc of both factions reveals the untenable character of their professed connection to history. For the Minutemen, their sense of connectedness to an American revolutionary spirit is perhaps admirable, but ultimately clouded by the fact that no sense of coherence concerning what constitutes 'America' exists in this future. The Brotherhood of Steel, meanwhile, may seek to assert military order as a means of reconstituting former glory (a past defined by militarism as a measure of progress) but in reality they can reign supreme only over the rubble of a lost civilization; there is no America to salvage, for either group.

Perhaps most interestingly, both factions might ultimately be responsible for repeating the very mistakes that have led the world of Fallout to its present state. The Minutemen are meant to embody the positive features of the American spirit: a desire for freedom and the building of a new world upon the principles of liberty and sacrifice. The Brotherhood embodies the more insidious manifestations of this process: the brute militarism, authoritarian edge, and violence that often come to define 'revolution'. In their desire to carve out a new future for the wastelands, either group must commit to continued violence and struggle to achieve control. Given that both are inspired by the same indelible faith in the 'American spirit,' both are vulnerable to falling prey to the very vices that came to define the anxiety and instability of the pre-war world. In employing the counterfactual to generate a fictional world that is in many ways a mirror not only of mid-century America, but that carries many of the tensions and fears that continue to define modern politics (unchecked capitalism, the military industrial complex, global instability), Fallout 4 throws into sharp relief the tenuousness of the stories that seek to construct 
and maintain order. The world of Fallout is not simply a rejection of narratives of progress, it is a caution to players about what is possible when these narratives remain unchallenged and uncontested. When historians write the past as linear, ordered, and moving towards a unified ideal - like Fukuyama's fated universal ideology - they (willingly or otherwise) participate in a process that seeks fundamentally to cement hierarchies of power and validate certain ways of knowing while disqualifying others. The world of Fallout 4 challenges players to think about what has led them here to this nuclear hellscape; this includes considering how it is that myths of progress that so often get written into history actively contributed in making a future that was less stable (and ultimately decimated) precisely because it was ideologically monolithic. The counterfactual in Fallout, then, serves both to illuminate a more honest representation of midcentury anxieties, and as a caution about what might happen in a world that does not interrogate the contingent and constructed nature of the dominant narratives which seek to order and reify relations of power and control in society.

\section{Conclusion}

The counterfactual presentation in Fallout is complicated by virtue of the fact that arguments can be made regarding multiple counterfactual interventions that the game makes in its construction and representation of the past. Scholar's like November (2013) for example, analyze the counterfactual in Fallout from the perspective of a technological break in the Fallout universe, raising the 'what if' question regarding what might have been, had atomic research continued post-war in a fevered pace (p. 298). As Marcus Schulzke (2013) points out in his research on video games and speculative history, however: "post-apocalyptic games, such as the games of the Fallout series, reimagine the Cold War in terms of the consequence of the nuclear war that might have happened," and further that, "this type of game situates the worst fears about nuclear war, the hope of fleeing destruction by retreating underground, and what life in the present might have been like had the Cold War gone differently" (p. 261). Certainly, this analysis has attempted to position Fallout 4 in these terms, while acknowledging other possible counterfactual interventions it may make, as a means of disrupting largely neoliberal attempts to whitewash Cold War history as a story of inevitable American victory and military/cultural supremacy. There remains however one unresolved question to which I now would like to turn, however briefly. Namely, what are the potential uses for this kind of game in an educational context, if any?

What Fallout 4 can offer to those audiences capable of engaging with its more mature content, is a set of loosely related narratives that position themselves within a single counterfactual gameworld. A truly complex and nuanced matrix of story, aesthetic and interactivity that can challenge players and raise legitimate and critical questions about history, as well as agency, authorship, memory, and subjectivity. If Fallout 4 fails to provide legitimate historical content in its counterfactual presentation, or if this content remains inaccessible to players unfamiliar with the 'real' history of the period (and both are subject to continued debate), its complex integration of multiple stories and its clever use of historical motifs and tropes, combined with the way that it employs the counterfactual to produce an alternative future, challenges players to think about how history gets made, both in the context of the game's story and non-virtual history. Consider again the Museum of Freedom, a building that clearly desires to produce and display a specific narrative of American progress and greatness; a true tribute to macho masculinity and glorious 
militarism. And yet, as the player bears witness to, this ideological jockeying is untenable: the building is half rubble, the statues and posing figures of war are covered in dust if not destroyed, and the paintings of past heroes are often unrecognizable. In interacting with a world where foundational myths have either disappeared or remain only as sardonic reminders of a past obsessed with a uniform doctrine of greatness and bombast (to its ruin), the player is provided with an opportunity not only to engage with but also to interrogate the world that extends itself before them. To consider how dominant narratives in Fallout built a future world obsessed with military prowess and over-consumption, while being reminded constantly of the kinds of futures that can unfold as a consequence of these doctrines remaining uncontested. Even as they seek to rebuild or at least pacify the wastelands, the player must carefully tread amongst and between factions that continue to cling to the very myths that ultimately engulfed the world in nuclear war. The conflicting presentation of histories - both real and imagined - in Fallout 4 provides an opportunity for the player to experience and interact with the game critically as a counterfactual reimagining a real historical period. Future research therefore should seek to study player experiences covering a broad spectrum, and use multiple assessment tools (interviews, play capture, questionnaires etc.) to determine the ways that Fallout engages users in a form of 'critical play' where learning becomes possible via engagement with this counterfactual storyspace and virtual world.

In his work on history games, Kevin Kee (2011) refers to the kinds of historical games that engage in the interrogation of 'objective history,' or those which upend the objectivist-empiricist position entirely via their design and content, as 'postmodern.' He argues that they "advocate a teaching of history in which students move beyond an assessment of the merits of an historical argument to the criteria underlying the historian's crafting of that argument, such as the decision to marshal or exclude evidence as it relates to the historian's thesis" (p. 430). It is this 'moving beyond' that most interests me in considering the potential that a game like Fallout 4 possesses for challenging dominant historical practices and narratives. The game presents history as ironic and bombastic. It is often playful in its presentation, but it is also deeply poignant in conveying to the player the severity of the consequences that are suffered because previous generations proved incapable of challenging dominant narratives and denying their solidifying into foundational myths. American greatness, centred around machismo militarism, runaway capitalism, and uniform culture (a culture of excess) built this alternative world, and ultimately destroyed it. Fallout 4 subverts expectations by generating a story that is at once a product of historical interpretation and at odds with it. In doing so, it invites (or at least opens up the playspace for) players to consider how historical arguments regarding the Cold War period (and the culture it participated in shaping) are inextricably linked to hierarchies of power and contests between competing ideologies. That is, they are not simply the story of what happened, but are fundamentally involved in shaping what does happen. History is implacably constitutive of political, cultural and social life, and this is born out in Fallout 4 where history is not merely the ruins and artifacts of a forgotten past. Rather, it continues to connect and inspire those who remain as they attempt to navigate, survive, and ultimately rebuild the wastelands, while simultaneously offering a warning against embracing the dogmatic practices that led this world to its present state. 


\section{References:}

Apperley, T. (2013). Modding the historians' code: Historical verisimilitude and the counterfactual imagination. In M. W. Kapell \& A. B. R. Elliot (Eds.), Playing with the past (pp. 185-198). London: Bloomsbury.

Aarseth, E. (1997). Cybertext: Perspectives on ergodic literature. Baltimore: Johns Hopkins University Press.

Bethesda Softworks. (2015). Fallout 4.

Bogost, I. (2007). Persuasive games: The expressive power of videogames. Cambridge: MIT Press.

Brown, H. J. (2008). Video games and education. New York: M.E. Sharpe.

Carr, E.H. (1964). What is history? Harmondsworth: Penguin.

Chapman, A. (2016). Digital games as history: How video games represent the past and offer access to historical practice. New York: Routledge.

Cutterham, T. (2013). Irony and American historical consciousness in Fallout 3. In M. W. Kapell \& A. B. R. Elliot (Eds.), Playing with the past (pp. 313-326). London: Bloomsbury.

Dannenberg, H. (2008). Coincidence and counterfactuality: Plotting time and space in narrative fiction. Lincoln: University of Nebraska Press.

De Groot, J. (2006). Empathy and enfranchisement: Popular histories. Rethinking History, 10(3), 391-413.

De Groot, J. (2008). Consuming history. London: Routledge.

Dolezel, L. (2010). Possible worlds of fiction and history: The postmodern stage. Baltimore: John Hopkins University Press.

Ferguson, N. (ed.). (1997). Virtual history: Alternatives and counterfactuals. New York: Basic books.

Foucault, M. (1977). Discipline and punish: The birth of the prison. New York: Random House.

Fukuyama, F. (1992). The end of history and the last man. New York: Free Press.

Galloway, A. (2006). Gaming: Essays on algorithmic culture. Minneapolis: University of Minnesota Press.

Gee, J. P. (2005). Why are video games good for learning? A paper presented at the University of Wisconsin-Madison.

Gee, J. P. (2003). What video games have to teach us about learning and literacy. New York: Palgrave/Macmillan.

Gee, J. P. (2007). Good video games + good learning: Collected essays on video games, learning and literacy. New York: Peter Lang.

Gee, J. P. \& Hayes, E. (2011). Language and learning in the digital age. London and New York: Routledge.

Harlan, D. (2007). Historical fiction and academic history, in K. Jerkins, S. Morgan, \& A. Munslow (Eds.), Manifestos for History (pp. 108-130). Abingdon: Routledge.

Hess, A. (2007). You don't play, you volunteer: Narrative public memory construction in Medal of Honor: Rising Sun. Critical Studies in Media Communication, 24(4) 339-356.

Jenson, J., Taylor, N., \& de Castell, S. (2011). Epidemic: Learning games go viral. Journal of the 
Canadian Association for Curriculum Studies, 8(11), 28-49.

Jenson, J., de Castell, S., Thumlert, K., \& Muehrer, R. (2016). Deep assessment: An exploratory study of game-based, multimodal learning in Epidemic. Digital Culture and Education, 8(1), 20-40.

Juul, J. (2005). Half-Real: Video Games between real rules and fictional worlds. Cambridge: MIT Press.

Kapell, W. M. \& Elliot, A. B. R. (Eds.). (2013). Playing with the past: Digital games and the simulation of history. London: Bloomsbury press.

Kee, K. \& Bachynski, J. (2009). Outbreak: Lessons learned from developing a "history game." Loading..., 4(3), 1-14.

Kee, K. (2011). Computerized history games: Narrative options. Simulation and Gaming, 42(4), 423-440.

Koski, J. (2017). Reflection of history: Representations of the Second World War in Valkyria Chronicles. Rethinking History, 21(3), 396-414.

Kramer, L. S. (1989). Literature, criticism, and historical imagination: The literary challenge of Hayden White and Dominick LeCapra. In L. Hunt (Ed.), The new cultural history. Berkley: University of California Press.

Lowenthal, D. (2007). The past of the future: From the foreign to the undiscovered country, in Manifestos for History (pp. 205-219). Abingdon: Routledge.

Lyotard, J. F. (1979). The postmodern condition: A report on knowledge. Manchester: Manchester University Press.

November, J. (2013). Fallout and yesterday's impossible tomorrow. In M. W. Kapell \& A. B. R.

Elliot (Eds.), Playing with the past (pp. 297-312). London: Bloomsbury.

Oakeshott, M. (1933). Experience and its modes. Cambridge University Press.

Phillips, M. S. (2013). On historical distance. New Haven: Yale University Press.

Rejack, B. (2007). Toward a virtual reenactment of history: Video games and the recreation of the past. Rethinking History, 11(3), 411-425.

Schulzke, M. (2013). Refighting the Cold War: Video games and speculative history. In M. W.

Kapell \& A. B. R. Elliot (Eds.), Playing with the past (pp. 261-276). London: Bloomsbury.

Sid Meier. (1991-2016). Civilization.

Spring, D. (2014). Gaming history: Computer and video games as historical scholarship. Rethinking History, 19(2), 207-221.

Squire, K. (2004). Replaying history: Learning world history through playing Civilization III. Dissertation submitted to the faculty of the School of Education: Instructional Systems Technology Department, Indiana University.

Squire, K. (2011). Video games and learning: Teaching and participatory culture in the digital age. Teachers College Press.

Steinkuehler, C., Squire, K. \& Barab, S. (Eds.) (2012). Games, learning, and society: Learning and meaning in the digital age. Cambridge University Press.

Thompson, E.P. (1978). The poverty of theory and other essays. Monthly Review Press.

Uricchio, W. (2005). Simulation, history, and computer games. In J. Raessens \& J. H. Goldstein (Eds.), Handbook of computer game studies (327-338). Cambridge: MIT press.

White, H. (1973). Metahistory: The historical imagination in nineteenth-century Europe. Baltimore: John Hopkins University Press.

Young, M.F., Slota, S., Cutter, A. B., Jalette, G., Mullin, G., Lai, B. ...Yukhymenko, M. (2012). Our princess is in another castle: A review of trends in serious gaming for education. Review of Educational Research, 82(1), 61-89. 